\title{
AC 2010-1189: USING IMPORTANCE-PERFORMANCE ANALYSIS METHOD TO EVALUATE THE FUNDAMENTAL CHEMISTRY COMPETENCE IN THE UNIVERSITIES OF SCIENCE AND TECHNOLOGY IN TAIWAN
}

\section{Kwannin Kuo, Lunghwa University of Science and Technology}

Kwannin Kuo is a lecturer in the department of Chemical and Materials Engineering at Lunghwa University of Science and Technology in Taiwan. He is also an EdD candidate in TESOL program at Queen's University, Belfast.

Pao-Chi Chen, Lunghwa University Science and Technology

Professor Chen is the Dean, College of Engineering at Lunghwa University of Science and Technology.

\section{Meei-Ruey Hsu, Ming-Chuan University}

Meei-Ruey Hsu is a professor in the department of Tourism at Ming-Chuan University in Taiwan. 


\section{Using Importance-Performance Analysis Method to Evaluate the Fundamental Chemistry Competence in the Universities of Science and Technology in Taiwan}

\section{Introduction}

On April 10 $0^{\text {th }}$ 1994, an Alliance for Education Reform Movement held a parade to cry out for an education reform in Taiwan. For more than a decade, the Taiwanese education system, from elementary schools to universities, has been reshaped by the education reform. There is no intention to depict the details of Taiwanese education reform. Nonetheless, the impact of changes in the higher education system needs to be noted. It provides crucial background for the purpose of this study. As one of the four major requests from the Alliance to promulgate education reform, increasing the number of universities later became one of the main policies targeted by Taiwanese Ministry of Education (MOE). In order to implement this policy, MOE in Taiwan lifted the restrictions on founding new universities and was keen to upgrade junior colleges to universities of science and technology. As a result, the increase of universities had an immense influence on higher education in Taiwan. Some statistics could exemplify the distinct change. There were a total of 171 colleges and universities (including colleges/universities of technology) in 2007 compared to only 53 in 1995 (Ministry of Education, 2008). Based on statistics from the Ministry of Interior (2009), the percentage of the population studying in colleges/universities (including junior colleges, colleges, universities and universities of science and technology) steeply rose from $34.76 \%$ of total population between age 20 and 24 to $65.23 \%$, making a $30.5 \%$ jump during the passing two decades. Currently, higher education opportunities are widely accessible in Taiwan, but ironically fierce competition, once happening among students who tried to squeeze into universities, has shifted to schools which are under pressure to recruit enough new students, in particular to those new colleges/universities of technology (Kuo, 2009).

Some critics claim that students in the new universities/universities of technology are not capable of being a university graduate. Likewise, it is generally believed by Taiwanese industries that the fundamental knowledge of chemistry by many graduates from universities of science and technology could not satisfy the industry demand. Accordingly, the present study aims to assess the fundamental chemistry knowledge of chemical engineering students in Taiwanese technical universities. The study will provide useful information about the real picture of students' fundamental chemistry competence. More importantly, the assessment was combined with an index of fundamental chemistry knowledge as established by a survey of experts. Thereby, the researchers argue that the assessment outcomes associated with the importance index of fundamental chemistry knowledge could be applied in the evaluation of current curriculum design for chemical engineering education as well as in the improvement of lecturers' instructions by means of the Importance-Performance Analysis (IPA) methods. 
IPA was proposed by Martilla \& James (1977). They plotted a two-axis figure with four quadrants as illustrated as Figure 1. One dimension represents "importance," another "performance." The four quadrants are characterized as "Concentrate here" (high importance, low performance), "Keep up the good work" (high importance, high performance), "Low priority" (low importance, low performance), and "Possible overkill" (low importance, high performance). This two-axis model is useful in management and delivery in higher education since it may clarify areas in which further effort is needed, i.e. "concentrate here" (Lewis, 2004).

\begin{tabular}{|c|c|c|}
\hline \multirow{2}{*}{ Importance } & Concentrate here & Keep up the good work \\
\hline & Low priority & Possible overkill \\
\hline
\end{tabular}

Figure 1 Importance-analysis model (Martilla \& James, 1977)

\section{Method}

Referred to textbooks, literatures, curricula, and experts' interviews, a questionnaire was devised as an importance index of fundamental chemistry competence. The questionnaire was sent to 18 experts in the first run and 14 experts in the second run to mark the importance of each item for a pilot study. The experts in the pilot study have at least ten-year working experience with chemistry-related fields. They include experts in industry, academic scholars, and researchers in institutes and $60 \%$ of them are $\mathrm{PhD}$. After that, a main study was conducted. The questionnaire was sent to a total of 105 experts to evaluate the importance of basic chemistry competence. Experts in the main study have at least some working experience with Chemistry-related fields in Taiwan. Based on the importance of fundamental chemistry competence confirmed by the expert survey, the researchers collected multiple-choice questions from various resources such as chemistry textbooks, entrance examination of universities, skill tests for certificates, etc. and implemented piloting tests for doing item analysis of these question items. Test items with negative discrimination indices were excluded. Furthermore, five experts were invited to assess the content validity of the items. Once the final version of the test was drown up, a total of 513 chemical engineering students from three universities of science and technology participated in the main test. More detailed depictions are delineated as follows:

\subsection{Questionnaire}

Underpinned by references such as textbooks (Silberberg, 1996; Hill \& Petrucci, 1999; Masterton \& Hurley, 2001), literature (Roam et al., 2007; Liu, 2006; Kim et al., 2008; James 
et al., 2008), current curricula (Shy, 2009) as well as experts' interviews, a questionnaire covering basic chemistry competence was designed, in which 28 topics have been indentified as illustrated on Table 1. It is necessary to clarify that the concept of basic chemistry competence in the present study is primarily about chemical knowledge which researchers can link to curriculum design or teaching content of chemistry in universities of science and technology.

Table 1 the basic chemistry competence

\begin{tabular}{|c|c|}
\hline Category & Topics \\
\hline \multirow[t]{5}{*}{ General Concept } & 1. Chemistry and Measurement \\
\hline & 2. Atom, Molecules and Ions \\
\hline & 3. Stoichiometry \\
\hline & 4. Gas and Gas Laws \\
\hline & 5. Thermochemistry \\
\hline \multirow{4}{*}{$\begin{array}{l}\text { Atomic and } \\
\text { Molecular } \\
\text { Structure }\end{array}$} & 6. Quantum Theory \\
\hline & 7. Electron Configuration and the Periodic Table \\
\hline & 8. Ionic Bonds and Covalent Bonds \\
\hline & 9. Molecular Structure and Bonding Theory \\
\hline \multirow[t]{3}{*}{ States of Matter } & 10. Liquids and Solids \\
\hline & 11. Solutions \\
\hline & 12. Metals and Nonmetal Materials \\
\hline \multirow{7}{*}{$\begin{array}{l}\text { Chemical } \\
\text { Kinetics and } \\
\text { Equilibrium }\end{array}$} & 13. Chemical Kinetics \\
\hline & 14. Chemical Equilibrium \\
\hline & 15. Acids and Bases \\
\hline & 16. Acid-Base Equilibrium \\
\hline & 17. Solubility and Equilibria Involving Complex Ions \\
\hline & 18. Thermodynamic \\
\hline & 19. Electrochemistry \\
\hline \multirow{2}{*}{$\begin{array}{l}\text { Chemistry of the } \\
\text { Elements }\end{array}$} & 20. Chemistry of the Elements \\
\hline & 21. The Transition Elements and Coordination Compounds \\
\hline \multirow{7}{*}{$\begin{array}{l}\text { Chemistry and } \\
\text { Life }\end{array}$} & 22. Nuclear Chemistry \\
\hline & 23. Organic Chemistry \\
\hline & 24. Polymer Chemistry \\
\hline & 25. Biochemistry \\
\hline & 26. Environmental Chemistry \\
\hline & 27. Energy \\
\hline & 28. Simulation of Chemistry \\
\hline
\end{tabular}


Table 2 the topics/ items in "fundamental chemistry concept" and their associated questions

\begin{tabular}{|c|c|c|}
\hline Topics & Items & Questions \\
\hline \multirow{2}{*}{$\begin{array}{l}\text { Chemistry and } \\
\text { Measurement }\end{array}$} & Knowing Chemistry & \multirow[t]{2}{*}{$1,2,3$} \\
\hline & Measurement and unit & \\
\hline \multirow{3}{*}{$\begin{array}{l}\text { Atom, Molecules and } \\
\text { Ions }\end{array}$} & Atomic theory and structure & \multirow{3}{*}{$\begin{array}{l}4,5,6,7,12,13,14, \\
50\end{array}$} \\
\hline & Chemical formula and nomenclature & \\
\hline & Chemical Equations & \\
\hline \multirow[t]{3}{*}{ Stoichiometry } & Mass and the mole of matter & \multirow{3}{*}{$\begin{array}{l}8,9,10,11,12,13 \\
14,59\end{array}$} \\
\hline & Mass relations in chemical formulas & \\
\hline & Stoichiometry & \\
\hline \multirow[t]{2}{*}{ Gas and Gas Laws } & Gas laws & \multirow[t]{2}{*}{$15,16,17,18$} \\
\hline & The kinetic-molecular theory & \\
\hline \multirow{2}{*}{$\begin{array}{l}\text { Electron Configuration } \\
\text { and the Periodic Table }\end{array}$} & Electron configuration & \multirow{2}{*}{$\begin{array}{l}19,20,51,52,53, \\
54,55,56,57,58, \\
60\end{array}$} \\
\hline & Periodic table & \\
\hline \multirow{2}{*}{$\begin{array}{l}\text { Ionic Bonds and } \\
\text { Covalent Bonds }\end{array}$} & Ionic bonds & \multirow[t]{2}{*}{$21,22,24$} \\
\hline & Covalent bonds & \\
\hline \multirow{2}{*}{$\begin{array}{l}\text { Molecular Structure } \\
\text { and Bonding Theory }\end{array}$} & Molecular structure and bonding theory & \multirow[t]{2}{*}{$26,27,28,29$} \\
\hline & Molecular orbitals & \\
\hline \multirow[t]{3}{*}{ Liquids and Solids } & The change of states of matter & \multirow[t]{3}{*}{$23,25,30$} \\
\hline & Liquid state & \\
\hline & Solid state & \\
\hline \multirow[t]{3}{*}{ Solutions } & Solution formation & \multirow{3}{*}{$\begin{array}{l}31,32,33,34,35 \\
36\end{array}$} \\
\hline & Colligative properties & \\
\hline & Colloids & \\
\hline \multirow{2}{*}{$\begin{array}{l}\text { Metals and Nonmetal } \\
\text { Materials }\end{array}$} & Metal and metallurgy & \multirow[t]{2}{*}{$37,25,38$} \\
\hline & Nonmetal materials & \\
\hline \multirow[t]{3}{*}{ Chemical Kinetics } & The definition and determination of reaction rate & \multirow{3}{*}{$\begin{array}{l}39,40,41,42,43, \\
44\end{array}$} \\
\hline & The rate law and reaction mechanisms & \\
\hline & The factors affecting reaction rate & \\
\hline \multirow[t]{3}{*}{ Chemical Equilibrium } & Chemical equilibrium & \multirow{3}{*}{$\begin{array}{l}45,46,47,48,49, \\
50\end{array}$} \\
\hline & The application of equilibrium constant & \\
\hline & Qualitative treatment: Le Chatelier's Principle & \\
\hline
\end{tabular}

The list in Table 1 consists of the contents in General Chemistry. In order to assess students' competence, each topic had to be further divided into several items in a range of 2 to 
7. As a result, it created a total of 94 items. The items were too numerous to be handled in just one study, and were categorized into 3 sections entitled "fundamental chemistry concept," "the knowledge of elements and compounds," and "organic chemistry" respectively. The main focus of the present study is on "fundamental chemistry concept." Table 2 tabulates 12 topics and the items included in the "fundamental chemistry concept."

In order to conduct a pilot study, the questionnaire was sent to 18 experts. These experts marked the importance of each item in light of their individual opinion. Subsequently, the outcomes of the first round and the questionnaire were sent to experts because the pilot study is implemented according to a modified Delphi method. In short, the approach consists of an expert survey conducted in two or more rounds and in the second and later rounds of the survey the results of the previous round are given as feedback (Cuhls, 2003). Afterward, the questionnaire was sent to a total of 105 experts to study experts' perspectives about the importance of fundamental chemistry competence for engineering graduates from universities of science and technology.

\subsection{The collection of question item bank}

By means of the expert surveys, the investigators created an importance index referring to the 30 items of fundamental chemistry competence. Out of the 30 items in the importance index, more than 300 multiple-choice questions were collected from various resources such as chemistry textbooks, entrance examination of universities, skill tests for certificates, etc. Afterward, they conducted two pilot tests for item analysis and excluded questions with negative discrimination indices. Furthermore, five experts are invited to assess the content validity of the items and to mark their opinion about the appropriateness of the items. In addition, an expert meeting was organized to decide the final version of 60 questions as illustrated in Appendix 1. The choice of 60 question items was made with consideration that the questions should be sufficient in order to cover the scope of the 12 topics. The connection between questions and testing topics has been illustrated on Table 2 but the total number of questions should not exceed students' patience in answering the questions. The test itself is not high-stake because the testing results had no influence on any students' final grade.

\subsection{Implementation of the main test}

Originally, the main test was targeted at 600 chemical engineering students at three universities of science and technology with 200 freshmen and sophomores for each university. However, the genuine participants in the main test are 513 since there were insufficient numbers of freshmen and sophomores for each university. The distribution of participants in each university has been tabulated in Table 3. 
Table 3 the distribution of participants in each universities

\begin{tabular}{|c|c|c|c|}
\hline University & Freshmen & Sophomores & Total \\
\hline A & 111 & 77 & 188 \\
\hline B & 83 & 88 & 171 \\
\hline C & 80 & 74 & 154 \\
\hline Total & 274 & 239 & 513 \\
\hline
\end{tabular}

Among them, University A is a public university of technology while University B and C are private institutions. Most students enrolled in technical universities are based on their performances in Technical and Vocational Educational System (TVS) Joint Entrance Examination. Normally, better performers on the TVS Joint Entrance Examination would prefer public institutes owing to their lower tuition fees. Accordingly, the performance of participants of three universities could be expected in the order of University A, B, C. This is why the three technical universities were selected because their students may represent relatively high, medium and relatively low achievement learners respectively.

The testing time was 70 minutes but most of students finished their tests within 60 minutes. Since the test had no bearing on students' grades, it was very possible that students carelessly answered questions or randomly guessed. To avoid such cases, the investigators with the aid of department heads in the University A and B, arranged for the students' teachers to be their examiners. In University C, though graduate students were the examiners, students' lecturer would appear at the outset to request that students answered questions carefully. The testing procedures were written down and given to the examiners in advance in order to make sure that all the examiners follow the same procedure. All the tests started with students reading and signing a simple consent form which explained the purpose of the study and the guarantee of confidentiality.

\section{Results and Discussions}

\subsection{Questionnaire}

The questionnaire was devised under a Likert Scale. Hence, when average points were calculated, five points were given for each mark of the most importance. In the same line, an important mark was given as four points, neutral as three points, less important as two points and least important as one point. In the pilot study, there were 18 experts returning the questionnaire in the first round and 14 experts replied in the second round. Two runs of expert survey were analyzed by statistical program, SPSS. The outcomes demonstrated the significant convergence of experts' opinions as manifested by Pearson correlation coefficient $r$ $=0.952, \mathrm{p}<0.001$ and $83.33 \%$ quartile deviation within 0.5 as shown in Table 4 . 
Table 4 Expert survey results in the pilot and main study

\begin{tabular}{|c|c|c|c|c|}
\hline & \multicolumn{2}{|c|}{ Pilot Study } & \multicolumn{2}{|c|}{ Main Study } \\
\hline & Average & Q. D. & Average & Q. D. \\
\hline Knowing Chemistry & 4.25 & 0.5 & 4.41 & 0.5 \\
\hline Measurement and unit & 4.468 & 0.5 & 4.53 & 0.5 \\
\hline Atomic theory and structure & 4.375 & 0.5 & 4.09 & 0.5 \\
\hline Chemical formula and nomenclature & 4.468 & 0.5 & 4.37 & 0.5 \\
\hline Chemical Equations & 4.468 & 0.5 & 4.30 & 0.5 \\
\hline Mass and the mole of matter & 4.625 & 0.5 & 4.34 & 0.5 \\
\hline Mass relations in chemical formulas & 4.406 & 0.5 & 4.18 & 0.5 \\
\hline Stoichiometry & 4.593 & 0.5 & 4.18 & 0.5 \\
\hline Gas laws & 4.406 & 0.5 & 4.07 & 1 \\
\hline The kinetic-molecular theory & 4 & 0.25 & 3.82 & 1 \\
\hline Electron configuration & 4.093 & 0.5 & 3.84 & 1 \\
\hline Periodic table & 4.312 & 0.5 & 4.37 & 0.5 \\
\hline Ionic bonds & 4.125 & 0.625 & 4.04 & 1 \\
\hline Covalent bonds & 4.093 & 0.625 & 4.10 & 1 \\
\hline Molecular structure and bonding theory & 3.468 & 0.5 & 3.72 & 1 \\
\hline Molecular orbitals & 3.5 & 0.5 & 3.66 & 0.5 \\
\hline The change of states of matter & 4.375 & 0.5 & 4.16 & 1 \\
\hline Liquid state & 4.312 & 0.5 & 4.24 & 0.5 \\
\hline Solid state & 4.281 & 0.5 & 4.24 & 0.5 \\
\hline Solution formation & 4.187 & 0.5 & 4.10 & 0.5 \\
\hline Colligative properties & 4.031 & 1 & 3.80 & 1 \\
\hline Colloids & 3.593 & 0.5 & 3.77 & 0.5 \\
\hline Metal and metallurgy & 3.687 & 0.625 & 3.82 & 1 \\
\hline Nonmetal materials & 3.718 & 0.625 & 3.90 & 1 \\
\hline $\begin{array}{l}\text { The definition and determination of reaction } \\
\text { rate }\end{array}$ & 4.343 & 0.5 & 4.05 & 0.5 \\
\hline The rate law and reaction mechanisms & 4.218 & 0.5 & 4.07 & 0.5 \\
\hline The factors affecting reaction rate & 4.25 & 0.5 & 4.04 & 1 \\
\hline Chemical equilibrium & 4.343 & 0.5 & 4.22 & 0.5 \\
\hline The application of equilibrium constant & 4.218 & 0.5 & 3.99 & 1 \\
\hline Qualitative treatment: Le Chatelier's Principle & 4.375 & 0.5 & 4.05 & 1 \\
\hline
\end{tabular}

As for the main study, a total of 105 experts replied to their questionnaires. The profile of these 105 experts was $51 \%$ academic scholars, $44 \%$ industrial experts and 5\% from research 
institutes. The average points of the main study have been tabulated in Table 4. The expert's perspectives between the pilot and main studies about the importance of each item are also convergent significantly as revealed by the Pearson coefficient $r=0.802, p<0.001$. However, the percentage of quartile deviation within 0.5 is down to $56.66 \%$ for the main study. According to Faherty's (1979) conception, he indicated that if quartile deviation is less than or equal to 0.6 it could be interpreted as highly convergent and as relatively convergent for quartile deviation falling between 0.60 and 1.0. This implies that experts' perceptions in the main study became less convergent than those in the pilot study. Nonetheless, it is still an acceptable result when we consider the survey base was extended in the main study.

With regard to individual items in the main study, "Knowing chemistry" and "Measurement and unit" were marked the highest scores. Likewise, other items such as "Chemical formula and nomenclature," "Chemical Equations," "Mass relations in chemical formulas," and "Periodic Table" had also high averages. Generally speaking, "Chemistry and Measurement," "Atom, Molecules and Ions," "Stoichiometry," and "Liquids and Solids" were the topics acknowledged by the experts as being relatively important chemistry concept. On the other hand, topics such as "Molecular Structure and Bonding Theory" and "Molecular Orbitals" which are more theoretically oriented were considered less important to the experts in relation to basic chemistry competence. This may imply that the in experts' points of view the chemistry competence that engineering students should acquire is basic.

\subsection{Test Results}

In terms of the probability of correct items, the test results of freshmen and sophomores at each university have been tabulated in Table 5. The probabilities were calculated by TESTER for Windows devised by Yu (2002).

Table 5 probability of item correct for each university

\begin{tabular}{|c|c|c|}
\hline University & Freshmen & Sophomores \\
\hline A & 0.66 & 0.75 \\
\hline B & 0.6 & 0.61 \\
\hline C & 0.44 & 0.58 \\
\hline
\end{tabular}

As shown in Table 5, students' performance at the three universities did follow the order of University A, B, and C. In addition, the total average of probability of correct items is 0.61 (61\%). The outcomes might provide some evidence that students' attitude toward the test may not be reckless, which could give credit to the validity of the testing results. The investigators then adopted the probability of correct items of each question linked to their items (or topics) as the students' performance indicators and the importance index from the expert survey to plot an IPA analysis as shown in Figure 2. The detailed data was listed in Appendix 2. 


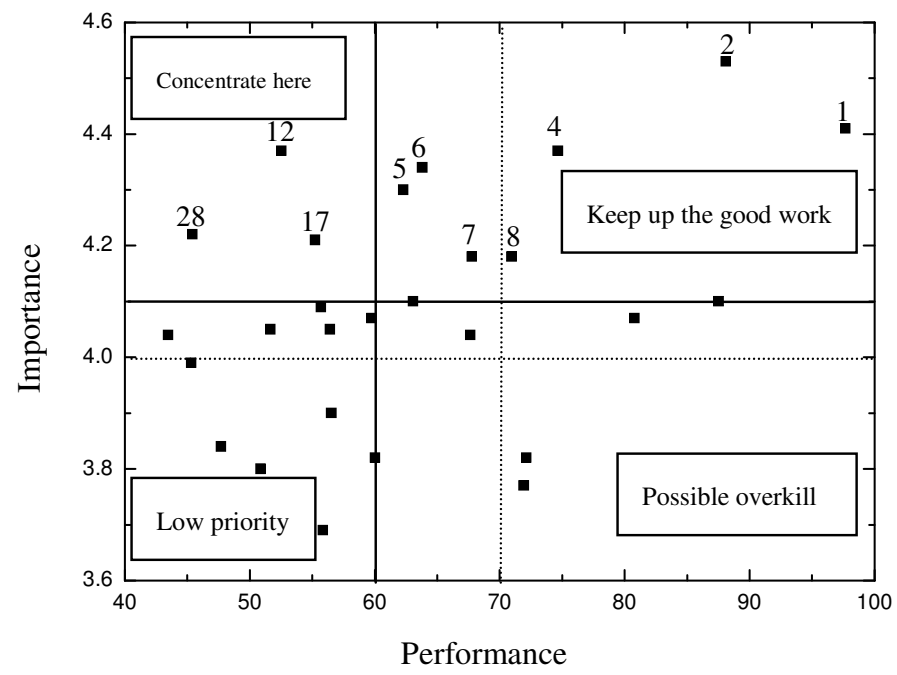

Figure 2 An IPA analysis of the present study

As noted in the introduction, the quadrant of "Concentrate here" implies that these items are highlighted as needing further attention. However, splitting the quadrants would profoundly affect how many items are located in the quadrant of "Concentrate here" as exemplified the different results of solid and dash split lines in Figure 2. Generally, middle lines are often chosen as the split line in the IPA; nonetheless, other alternatives might also be rational, depending on the reasons that researchers give. As shown in Figure 2 with the solid lines, the investigators split the quadrants with the middle line on the axis of importance but at $60 \%$ instead of the middle line of $70 \%$ on the axis of students' performance. $60 \%$ is normally the cut-off point of pass or fail in Taiwanese education system. In addition, the average probability of correct items is $61 \%$ in the present study. As a consequence, there are three items of fundamental chemistry competence that fall within the quadrant of "Concentrate here," namely "Periodic table," "Liquid state and solid states," and "Chemical equilibrium."

However, we need to be more deliberate when we interpret the outcome. The performance indicators are underpinned by the probability of correct items. If there are only limited questions, it is possible that performance could be drawn down by a single difficult question. So while we check the number of questions related to the topic on Table 2, there are only three questions linked to the topic, "Liquid state and solid state", compared with eight for "Periodic table" and six for "Chemical equilibrium." That is to say, students' performance on "Liquid state and solid states" may need to be further confirmed by more questions. While compared with the case of "Liquid state and solid state," it may be more reliable to say "Periodic table" and "Chemical equilibrium" are two prior chemical fundamental competences which should 
be reinforced.

\section{Conclusion}

This study focused on fundamental chemistry competence in 12 topics with 30 items. By means of a modified Delphi method, the investigators devised an importance index of fundamental chemistry competence. Two rounds of expert survey were completed for the pilot study of the questionnaire and with the aid of 105 experts. The importance indices of fundamental chemistry competence were investigated in the main study. Topics such as "Chemistry and Measurement," "Atom, Molecules and Ions," "Stoichiometry," and "Liquids and Solids" were revealed by the experts as being relatively important basic chemistry competence.

Throughout the process of collecting, pilot tests and expert examining, 60 questions connected to the 12 topics were selected and used in a paper-and-pencil test. A total of 513 participants from chemical engineering department in three universities of science and technology in Taiwan took the examination. Combining the results of expert surveys as importance indicators and the outcomes of the test as performance indicators, the researchers conducted an Importance-Performance Analysis (IPA) and revealed that "Periodic table" and "Chemical equilibrium" were two prior fundamental chemistry competences needing reinforcement.

The researchers are fully aware that one needs to be deliberate in order to interpret the findings of this study. Owing to the limited number of questions, the researchers were unable to test full contents of the 12 topics. Nonetheless, the expert survey and the IPA analysis do provide useful information for other chemical engineering programs. For instance, from the points of view of experts, the chemistry competence that engineering students should acquire is indeed basic. "Periodic table" and "Chemical equilibrium" were two prior fundamental chemistry competences needing reinforcement. More importantly, the methods adopted in the

present study may illustrate an approach to connect industrial demand and academic instruction.

\section{ACKNOWLEDGEMENT}

The authors gratefully acknowledge the financial supports provided by the National Science Council of the Republic of China under grant NSC 97-2511-S-262-008-MY3. 


\section{REFERENCES}

Cuhls, K. (2003). Delphi method. Technical report, Germany: Fraunhofer Institute for Systems and Innovation Research.

Faherty, V. (1979), Continuing Social Work Education: Results of a Delphi Survey, Journal of Education for Social Work, 15(1), 12-19.

Hill, J. W. \& Petrucci, R. H. (1999, $2^{\text {th }}$ edn.). General Chemistry: An Integrated Approach, Upper Saddle River, NJ: Prentice Hall Inc.

James R., MacArthur and Loretta L. Jones (2008). A review of literature reports of clickers applicable to college chemistry classrooms, Chem. Educ. Res. Pract., 9, 187-195.

Kim B., Saalman E., Christie M., Ingerman A. \& Linder C. (2008). SimChemistry as an active learning tool in chemistry education, Chem. Educ. Res. Pract., 9, 277-284.

Kuo, K. (2009). The academic performances of senior and vocational high school graduate students in the department of Chemical and Material Engineering of Lunghwa University, Journal of Lunghwa University of Science and Technology, 28, 39-51.

Lewis, R. (2004). Importance-performance analysis, Australasian J. of Engng. Educ. Online publication 2004-01, Attained from http://www.aaee.com.au/journal/2004/lewis04.pdf

Liu, K. T. (2006). Teaching sustainable (green) chemistry at university level, Chemistry (The Chinese Chem. Soc., Taipei), 64(1), 141-145.

Martilla, A. H., James, J.C. (1997). Importance-performance analysis, Journal of Marketing, 41, 77-79.

Masterton, W. L. \& Hurley, C. N. (2001, $4^{\text {th }}$ edn.). Chemistry: Principles and Reactions, Orlando, FL: Harcourt College Publishers.

Ministry of Education (2008). Education in Taiwan 2008. Taipei, Taiwan: Ministry of Education.

Ministry of Interior (2009). Statistics Weekly Information $\left(12^{\text {th }}\right.$ week). Taipei, Taiwan: Ministry of Interior

Roam G. D., Wu. W. Y., \& Yang, C. Y. (2007). Technologies derived from green chemistry, Chemistry (The Chinese Chem. Soc., Taipei), 65(4), 343-354.

Shy, L. Y. (2009). The study of Chemistry curricula and its improvement, Final report, Taiwan: National Science Council.

Silberberg, M. (1996). Chemistry: The Molecular Nature of Matter and Change, St. Louis, MO: Mosby-Year Book, Inc.

Yu, M. (2002), Educational testing and assessment: Achievement test and teaching assessment. Taipei, Taiwan: Psychological Publishing Co., Ltd. 
Appendix 1 Chemistry Questions

1. Which of the following is a chemical change?
(1) Ice dissolving
(2) Iodine sublimation
(3) Water boiling
(4) Magnesium burning

2. Which of the following is pure substance?
a. Orange juice
b. Steam
c. Wine
d. carbon dioxide
e. gasoline
(1) a, c
(2) $b, d$
(3) a,c,d
(4) d,e

3. Which of the following is the unit of reaction rate?
(1) $M$
(2) $\mathrm{mol} / \mathrm{l}$
(3) $\mathrm{mol} / \mathrm{l} \cdot \mathrm{hr}$
(4) $\mathrm{mol} / \mathrm{ml}$

4. The development of atomic theory is a series of early experiments designed to help "to see what can not be seen, to understand something difficult to be understood." Which of the following combination of scientists and their major scientific discoveries or theories is wrong?

\begin{tabular}{|c|l|l|}
\hline Options & Scientists & \multicolumn{1}{c|}{ Published the contents of the } \\
\hline$(1)$ & Dalton & advocated atomic theory \\
\hline$(2)$ & Thomson & discovered electrons \\
\hline$(3)$ & Rutherford & proposed atomic structure model \\
\hline$(4)$ & Mendeleev & proposed the meaning of the atomic number \\
\hline
\end{tabular}

5. Which of the following description is correct?

(1) Protons have a negative charge, while neutrons have no charge

(2) The mass of a neutron and an electron is equal

(3) When atoms change into ions, the number of protons remains unchanged

(4) The mass of the electron is more than that of the proton

6. The electronic nature of which material is equal to $\mathrm{Be}^{2+} ?(1) \mathrm{F}^{-} \quad(2) \mathrm{N}^{-3}$ (3) $\mathrm{He} \quad$ (4) $\mathrm{Ne}$

7. Which of the following is the chemical formula of ferrous chloride? (1) $\mathrm{FeCl}_{4}$ (2) $\mathrm{FeCl}_{3}$ (3) $\mathrm{FeCl}_{2}$ (4) $\mathrm{FeCl}$

8. 2 grams of which of the following has the most atoms? (Atomic mass: $\mathrm{H}=1, \mathrm{C}=12, \mathrm{~N}=$
$14, \mathrm{O}=16)(1) \mathrm{H}$
(2)C
(3) $\mathrm{O}$
(4) $\mathrm{N}$

9. Which of the following consists of the largest number of hydrogen atoms? (Avogadro's number is $6.02 \times 10^{23}$ )
(1) $3.01 \times 10^{23}$ hydrogen molecules
(2) $5.02 \times 10^{23}$ Hydrogen atoms
(3) 8.5 grams of ammonia $\left(\mathrm{NH}_{3}\right)$
(4) 8 grams of methane $\left(\mathrm{CH}_{4}\right)$

10. A compound was found to contain $40.9 \%$ carbon, $4.6 \%$ hydrogen and $54.5 \%$ oxygen, (the above \% weight percentage). Which of the following is its empirical formula? (Atomic mass: $\mathrm{C}=12, \mathrm{O}=16, \mathrm{H}=1$ )
(1) $\mathrm{C}_{2} \mathrm{H}_{6} \mathrm{O}$
(2) $\mathrm{C}_{3} \mathrm{H}_{4} \mathrm{O}_{3}$
(3) $\mathrm{C}_{3} \mathrm{H}_{6} \mathrm{O}_{2}$
(4) $\mathrm{C}_{4} \mathrm{H}_{9} \mathrm{O}$

11. A compound contains only three kinds of elements, $\mathrm{C}, \mathrm{H}, \mathrm{O}$. If 4.6 grams of this 
compound generated 8.8 grams of $\mathrm{CO}_{2}(\mathrm{~g})$ and $5.4 \mathrm{~g} \mathrm{H}_{2} \mathrm{O}(\mathrm{g})$ after complete combustion, which of the following is its empirical formula? (Atomic mass: $\mathrm{C}=12, \mathrm{O}=16, \mathrm{H}=1$ )
(1) $\mathrm{C}_{4} \mathrm{H}_{8} \mathrm{O}$
(2) $\mathrm{C}_{2} \mathrm{H}_{6} \mathrm{O}$
(3) $\mathrm{C}_{4} \mathrm{H}_{10} \mathrm{O}$
(3) $\mathrm{C}_{5} \mathrm{H}_{10} \mathrm{O}_{2}$

12. In order to produce methanol $\left(2 \mathrm{H}_{2}(\mathrm{~g})+\mathrm{CO}(\mathrm{g}) \rightarrow \mathrm{CH}_{3} \mathrm{OH}(\mathrm{g})\right), 68 \mathrm{~g}$ of $\mathrm{CO}$ and $8.3 \mathrm{~g}$ of $\mathrm{H}_{2}$ were used, how many grams of methanol could be obtained after the reaction?
(1) $39 \mathrm{~g}$
(2) $66 \mathrm{~g}$
(3) $78 \mathrm{~g}$
(4) $132 \mathrm{~g}$

13. After equation $\mathrm{NH}_{3}(\mathrm{~g})+\mathrm{O}_{2}(\mathrm{~g}) \rightarrow \mathrm{NO}_{2}(\mathrm{~g})+\mathrm{H}_{2} \mathrm{O}(\mathrm{g})$ was balanced, what is the coefficient of $\mathrm{O}_{2}(\mathrm{~g})$, if the coefficients among molecules are the smallest ratio? (1)3
(2) 6
(3) 7
(2) 9

14. In $2 \mathrm{NaN}_{3}(\mathrm{~s}) \rightarrow 2 \mathrm{Na}(\mathrm{s})+3 \mathrm{~N}_{2}$ (g) reaction, the reactants can be completely decomposed, how many grams of $\mathrm{NaN}_{3}$ are needed to produce 14.0 grams of $\mathrm{N}_{2}$ ? (Atomic mass: $\mathrm{N}=$
$14, \mathrm{Na}=23$ ) (1) 21.7
(2) 32.5
(3) 43.3
(4) 97.5

15. At 2 atm and $27^{\circ} \mathrm{C}$, what is the molecular mass of a gas with density 4.0 grams/liter?
(1) 49.2
(3) 38.2
(3) 29.7
(4) 22.9

16. Molecular mass of gas $A$ is 16 and of gas $B$ is 36 . What is the ratio of diffusion rate for two gases at same temperature?
(1) 0.5
(2) 1
(3) 1.5
(4) 2

17. A constant volume of gas was inserted into a container. When the gas temperature rises, which of the following will not change?

(1) Gas kinetic energy (2) Gas density (3) Gas pressure (4) Between the collision frequency of gas molecules

18. Under the same temperature and pressure, how many times is the diffusion rate of methane to that of oxygen? (Atomic mass: $\mathrm{H}=1, \mathrm{C}=12, \mathrm{O}=16$ )
(1) 21
(2) 2
(3) 21
(4) 2

19. Which of the following is the electronic configuration of calcium atom?
(1) $1 S^{2} 2 S^{2} 2 p^{6} 3 S^{2} 3 p^{6} 3 d^{2}$
(2) $1 \mathrm{~S}^{2} 2 \mathrm{~S}^{2} 2 \mathrm{p}^{6} 3 \mathrm{~S}^{2} 3 \mathrm{p}^{6} 4 \mathrm{~S}^{2}$
(3) $1 S^{2} 2 S^{2} 2 p^{6} 3 S^{2} 3 p^{6} 3 f^{2}$
(4) $1 \mathrm{~S}^{2} 2 \mathrm{~S}^{2} 2 \mathrm{p}^{6} 3 \mathrm{~S}^{2} 3 \mathrm{p}^{6} 4 \mathrm{~d}^{2}$

20. Which of the following contains unpaired electron when an atom is at the ground state?
(1) $\mathrm{He}$
(2) $\mathrm{Be}$
(3) $\mathrm{C}$
(4) $\mathrm{Ne}$

21. Which of the following is an ionic compound?
(1) $\mathrm{HCl}$
(2) $\mathrm{AlCl}_{3}$
(3) $\mathrm{CH}_{3} \mathrm{OH}$
(4) $\mathrm{H}_{2} \mathrm{SO}_{4}$

22. Two atoms sharing valence electrons to form a chemical bond is called (1) Ionic bond (2) Covalent bond (3) Metal bond (4) Hydrogen bond

23. Which of the following liquid properties increase with temperature?

(1) Vapor Pressure (2) Surface tension (3) Viscosity (4) Molecular weight

24. In the crystal lattice of Sodium Chloride, each chloride ion is surrounded by six sodium ions and each sodium ion is surrounded by six chloride ions. How many chloride ions would a chloride ion be surrounded by? 

(1) 6
(2) 8
(3) 10
(4) 12

25. Which of the following concerning the description of crystalline silicon is incorrect?

(1) The crystal structure of pure silicon at low temperature similar is to that of the diamond.

(2) Pure silicon crystals at low temperature can not be conductive, but can be conductive after they were heated to high temperature.

(3) At room temperature, the impure-type semiconductor silicon crystal is more conductive than the pure silicon crystal.

(4) When traces of arsenic (As) atom were added into pure silicon crystal (with five valence electrons), a p-type semiconductor would be formed.

26. Which of the following is a polar molecule?
(1) $\mathrm{SO}_{3}$
(2) $\mathrm{CHCl}_{3}$
(3) $\mathrm{CH}_{4}$
(4) $\mathrm{C}_{2} \mathrm{H}_{4}$

27. Which of the following is a non-polar molecule?
(1) $\mathrm{CH}_{4}$
(2) $\mathrm{HCl}$
(3) $\mathrm{NH}_{3}$
(4) $\mathrm{H}_{2} \mathrm{O}$

28. Among the following compounds, which can generate hydrogen bonds?

(1) Acetic acid (2) Propane (3) Carbon dioxide (4) Acetone

29. The driving force between $\mathrm{NH}_{3}$ and $\mathrm{C}_{6} \mathrm{H}_{6}$ is (1) Dispersion force

(2) Dipole - dipole forces (3) Ion - dipole forces (4) Hydrogen bonds

30. What is it called when solid $\mathrm{CO}_{2}$ at 1 atm is heated to $-78^{\circ} \mathrm{C}$ ?

(1) Sublimation (2) Boiling (3) Freezing (4) Gasification

31. How many grams of hydrogen chloride will be needed to prepare $500 \mathrm{ml}$ of a $2 \mathrm{M}$ hydrochloric acid solution? (atomic mass: $\mathrm{H}=1, \mathrm{Cl}=35.5$ )
(1) 3.65
(2) 7.30
(3) 14.6
(4) 36.5

32. What is the Molality (m) of $\mathrm{CuSO}_{4}$ when 50 grams of $\mathrm{CuSO}_{4} \cdot 5 \mathrm{H}_{2} \mathrm{O}$ dissolve in 182 grams of water? (atomic mass: $\mathrm{Cu}=64, \mathrm{~S}=32, \mathrm{H}=1, \mathrm{O}=16$ )
(1) 2.0
(2) 1.5
(3) 1.0
(4) 0.5

33. 1.0 grams of an organic compound is dissolved in 10 grams of Benzene and becomes a homogeneous solution. The freezing point of the solution is lower than that of Benzene by $2.56{ }^{\circ} \mathrm{C}$. What is the molecular mass of the organic compound? (the freezing point depression constant of Benzene is $5.12{ }^{\circ} \mathrm{C} / \mathrm{m}$ )
(1) 200
(2) 100
(3) 20
(4) 10

34. At $25^{\circ} \mathrm{C}$, the vapor pressure of pure water is $24 \mathrm{mmHg}$. If 92 grams of glycerol (molecular mass is 92 and non-volatile solution is assumed) are taken to dissolve in 342 grams of water and form ideal solution, while at the same temperature, how many $\mathrm{mmHg}$ vapor pressure of this solution would decrease? ( atomic mass: $\mathrm{H}=1, \mathrm{O}=16$ )
(1) 0.4
(2) 0.6
(3) 1.2
(4) 2.4

35. 20 grams of starch can be completely dissolved in water to produce one liter of solution, if at $27^{\circ} \mathrm{C}$ the osmotic pressure is measured as $0.02 \mathrm{~atm}$, what is the molecular mass of 
the starch? (Ideal gas constant $\mathrm{R}=0.082 \mathrm{~atm}-\mathrm{L} / \mathrm{K} \cdot \mathrm{mole}$ )
(1) 32800
(2) 24600
(3) 16400
(4) 8200

36. Which of the following is a colloidal solution?

(1) Ethanol solution (2) Ammonia (3) Syrup (4) Milk

37. Which of the following is composed of alloy brass?

(1) $\mathrm{Cu}$ and $\mathrm{Mn}$ (2) $\mathrm{Cu}$ and $\mathrm{Zn} \mathrm{(3)} \mathrm{Cu}$ and $\mathrm{Au}$ (4) $\mathrm{Cu}$ and $\mathrm{Sn}$

38. Which of the following is the main component of stalagmites and stalactites?

(1) $\mathrm{CaCO}_{3}$ (2) $\mathrm{Na}_{2} \mathrm{CO}_{3}$ (3) $\mathrm{CaSO}_{4}$ (4) $\mathrm{Na}_{2} \mathrm{SO}_{4}$

39. The formula of a $3^{\text {rd }}$ reaction rate is $\mathrm{k}[\mathrm{A}][\mathrm{B}]^{2}$, which of the following is the unit of its rate constant?

(1) $[\text { concentration }]^{-3}[\text { time }]^{-1}(2)[\text { concentration }]^{-2}[\text { time }]^{-1}(3)[\text { concentration }]^{-1}[\text { time }]^{-1}(4)$ [time $^{-1}$

40. Reaction equation: $2 \mathrm{H}_{2}(\mathrm{~g})+\mathrm{O}_{2}(\mathrm{~g}) \rightarrow 2 \mathrm{H}_{2} \mathrm{O}(\mathrm{g})$, which of the following indicates its reaction rate?
(1) $\frac{1}{2} \times \frac{\Delta\left[H_{2}\right]}{\Delta t}(2) \frac{-\Delta\left[H_{2}\right]}{\Delta t}$
(3) $\frac{\Delta\left[O_{2}\right]}{\Delta t}$
(4) $\frac{1}{2} \times \frac{\Delta\left[\mathrm{H}_{2} \mathrm{O}\right]}{\Delta t}$

41. Concerning the chemical reaction $2 \mathrm{~A}+2 \mathrm{~B} \rightarrow \mathrm{C}$, two experiments were confirmed. In the first experiment, the concentrations of both reactants $\mathrm{A}$ and $\mathrm{B}$ were doubled, resulting in an increase of the rate by eight times. In the second experiment, the concentration of only reactant $\mathrm{A}$ was doubled, resulting in an increase of the rate by two times. The reaction rate is equal to which of the following? $(\mathrm{k}=$ reaction rate constant)
(1) $\mathrm{k}[\mathrm{A}]^{2}[\mathrm{~B}]^{2}$
(2) $\mathrm{k}[\mathrm{A}][\mathrm{B}]^{2}$
(3) $\mathrm{k}[\mathrm{A}]^{2}[\mathrm{~B}]$
(4) $\mathrm{k}[\mathrm{A}][\mathrm{B}]$

42. The reaction equation $\mathrm{A}+\mathrm{B} \rightarrow \mathrm{C}$ of the reaction rate is $\mathrm{k}[\mathrm{A}]^{2}[\mathrm{~B}]$, initial concentration of $[\mathrm{A}]=1.5 \mathrm{M},[\mathrm{B}]=1.0 \mathrm{M}$ when the initial reaction rate of $\mathrm{R}$, if replaced by $[\mathrm{A}]=[\mathrm{B}]=$ $0.5 \mathrm{M}$ for the initial concentration of the initial rate of reaction be?
(1) $\frac{R}{9}$
(2) $\frac{R}{18}$
(3) $\frac{R}{15}$
(4) $\frac{R}{9}$

43. If the temperature increased $10^{\circ} \mathrm{C}$, the reaction rate doubled. How many times will the reaction rate increase if the temperature increases $50{ }^{\circ} \mathrm{C}$ ?
(1) 5
(2) 10
(3) 32
(4) 64

44. Which of the following does not affect the reaction rate?

(1) activation energy (2) catalyst (3) temperature (4) reaction heat

45. The chemical reaction $\mathrm{N}_{2}(\mathrm{~g})+3 \mathrm{H}_{2}(\mathrm{~g}) \rightarrow 2 \mathrm{NH}_{3}$ is contained in a vacuum closed container. Which of the following processes can not attain the above chemical equilibrium? (1)put in $2.5 \mathrm{~mol} \mathrm{~N}_{2}(\mathrm{~g})$ and $2.5 \mathrm{~mol} \mathrm{H}_{2}(\mathrm{~g}) \quad$ (2)put in $2.5 \mathrm{~mol} \mathrm{~N}_{2}(\mathrm{~g})$ and $5.0 \mathrm{~mol} \mathrm{NH}_{3}(\mathrm{~g})$

(3)put in $5.0 \mathrm{~mol} \mathrm{NH}_{3}(\mathrm{~g}) \quad$ (4)put in $7.5 \mathrm{~mol} \mathrm{H}_{2}(\mathrm{~g})$

46. A equilibrium reaction $\mathrm{A}(\mathrm{g})+2 \mathrm{~B}(\mathrm{~g}) \rightarrow \mathrm{C}(\mathrm{g})+\mathrm{D}(\mathrm{l})$ was conducted in a closed system and $\Delta \mathrm{H}<0$ has been known. Which of the following description is correct? 
(1) Temperature rises, the equilibrium constant increases, and the balance shifts right

(2) The reaction is an endothermic reaction

(3) At constant temperature, $\mathrm{A}(\mathrm{g})$ is added and the balance shifts left

(4) At constant temperature, the volume shrinks and the balance shifts right

47. There is a reaction $A^{3+}+3 B^{-} \Leftrightarrow 2 C^{+}+2 D^{-}$in equilibrium. If the concentrations of reactants and products are $\left[\mathrm{A}^{3+}\right]=0.1 \mathrm{M},\left[\mathrm{B}^{-}\right]=0.2 \mathrm{M},\left[\mathrm{C}^{+}\right]=0.1 \mathrm{M}$, and $\left[\mathrm{D}^{-}\right]=0.2 \mathrm{M}$, what is the value of equilibrium constant?

(1) 4 (2) 2 (3) 1 (4) 0.5

48. At constant temperature, the equilibrium constant $\mathrm{K}_{\mathrm{c}}$ is 4.5 . In a liter container, how many moles $\mathrm{Z}(\mathrm{g})$ should be added if 2 moles $\mathrm{Y}(\mathrm{g})$ are measured at equilibrium status?
(1) 12
(2) 16
(3) 20
(4) 24

49. Which of the following factors will change the equilibrium constant of the reaction $\mathrm{N}_{2} \mathrm{O}_{4}(\mathrm{~g})+14.1 \mathrm{Kcal} \Leftrightarrow 2 \mathrm{NO}_{2}(\mathrm{~g})$ ?

(1) expand the total volume of the system

(2) add $\mathrm{N}_{2} \mathrm{O}_{4}(\mathrm{~g})$ into the system under constant pressure

(3) change the temperature of the system

(4) add $\mathrm{He}(\mathrm{g})$ into the system under constant pressure

50. In a closed system, which of the following chemical reaction may shift to right when the volume is decreased under constant temperature?
(1) $\mathrm{H}_{2}(\mathrm{~g})+\mathrm{Cl}_{2}(\mathrm{~g}) \quad \rightarrow \quad 2 \mathrm{HCl}(\mathrm{g})$
(2) $2 \mathrm{SO}_{2}(\mathrm{~g})+\mathrm{O}_{2}(\mathrm{~g}) \rightarrow 2 \mathrm{SO}_{3}(\mathrm{~g})$
(3) $2 \mathrm{NH}_{3}(\mathrm{~g}) \rightarrow \mathrm{N}_{2}(\mathrm{~g})+3 \mathrm{H}_{2}(\mathrm{~g})$
(4) $4 \mathrm{Fe}(\mathrm{s})+3 \mathrm{O}_{2}(\mathrm{~g}) \rightarrow 2 \mathrm{Fe}_{2} \mathrm{O}_{3}(\mathrm{~s})$

51. In the periodic table, which group does Phosphorus belong to?
(1) VIIIA
(2) VA
(3) IIIA
(4) IA

52. Which of the following symbols are in the correct order of these elements [boron, titanium, chromium, arsenic, krypton]?
(1) $[\mathrm{Ba}, \mathrm{Ti}, \mathrm{Ca}, \mathrm{Ar}, \mathrm{Cr}]$
(2) $[\mathrm{Be}, \mathrm{Ni}, \mathrm{Cs}, \mathrm{Sn}, \mathrm{Cr}]$
(3) $[\mathrm{Br}, \mathrm{Li}, \mathrm{Cf}, \mathrm{Am}, \mathrm{K}]$
(4) $[\mathrm{B}, \mathrm{Ti}, \mathrm{Cr}, \mathrm{As}, \mathrm{Kr}]$

53. Of the following properties of the alkali metal group, which one decreases with the increase of the atomic number?

(1) atomic mass (2) atomic radius (3) ionic radius (4) the first ionization energy

54. Which the following description is correct for periods in the periodic table?

(1) elements in the same period have similar chemical properties

(2) the longest period in the periodic table is the fifth period

(3) Nitrogen group elements have five valence electrons in Group A elements.

(4) The metal property gradually increases from left to right in the same period

55. The periodic table was arranged by the sequence of the atomic number. Which of the following description is correct?

(1) Nonmetallic property gradually increases from top to down in the same group. 
(2) The atomic radius of elements in the third period decreases from left to right

(3) Atoms will have the same mass number if they are the same element.

(4) In the same period, the first ionization energy of later element must be larger than that of the former one.

56. The chemical properties of which following element are similar to that of the element having atomic number 34? (1) fluoride (2) oxygen (3) nitrogen (4) carbon

57. Table 1 shows a part of the periodic table. A to E are element symbols, in which A's atomic number is 13 . Therefore, which element has the smallest atomic radius?

(1) A (2) B (3) C (4) D

\begin{tabular}{|l|l|l|}
\multicolumn{1}{c}{} & Table 1 \\
\cline { 2 - 3 } \multicolumn{1}{c|}{} & A & B \\
\hline C & D & E \\
\hline
\end{tabular}

58. Which of the following description is correct?

(1) Fluoride has the largest electronegativity

(2) atoms in the same period have similar chemical properties

(3) atoms will be easier to lose electrons if they have larger ionization energy

(4) the first ionization energy of atoms is greater than the second dissociation

There are two isotopes of an element. $19.91 \%$ is ${ }_{5}^{10} \mathrm{X}$ and the mass is $10.0129 \mathrm{amu}$; another

$80.09 \%$ is ${ }_{5}^{11} \mathrm{X}$ and the mass is $11.0093 \mathrm{amu}$. Based on the above information, please answer questions 59-60.

59. What is the atomic mass for the element $X$ ? $\quad$ (1) 11.01 (2) $10.01 \quad$ (3) 10.51 (4) 10.81

60. How many valence electrons $X$ atom has? (1) $5 \quad$ (2) $4 \quad$ (3) $3 \quad$ (4) 2 


\begin{tabular}{|c|c|c|c|}
\hline \multirow{2}{*}{\multicolumn{2}{|c|}{$\begin{array}{l}\text { Appendix } 2 \\
\text { Items or Topics }\end{array}$}} & \multicolumn{2}{|c|}{ Indicators } \\
\hline & & \multirow{2}{*}{$\begin{array}{c}\text { Importance } \\
4.41\end{array}$} & \multirow{2}{*}{$\begin{array}{c}\text { Performance }(\%) \\
97.66\end{array}$} \\
\hline 1 & Knowing Chemistry & & \\
\hline 2 & Measurement and unit & 4.53 & 88.11 \\
\hline 3 & Atomic theory and structure & 4.09 & 55.69 \\
\hline 4 & Chemical formula and nomenclature & 4.37 & 74.66 \\
\hline 5 & Chemical Equations & 4.30 & 62.28 \\
\hline 6 & Mass and the mole of matter & 4.34 & 63.81 \\
\hline 7 & Mass relations in chemical formulas & 4.18 & 67.77 \\
\hline 8 & Stoichiometry & 4.18 & 70.96 \\
\hline 9 & Gas laws & 4.07 & 80.80 \\
\hline 10 & The kinetic-molecular theory & 3.82 & 72.13 \\
\hline 11 & Electron configuration & 3.84 & 47.69 \\
\hline 12 & Periodic table & 4.37 & 52.53 \\
\hline 13 & Ionic bonds & 4.04 & 43.47 \\
\hline 14 & Covalent bonds & 4.10 & 87.52 \\
\hline $15-16$ & Molecular Structure and Bonding Theory & 3.69 & 55.85 \\
\hline $17-19$ & Liquid State and Solid State & 4.21 & 55.23 \\
\hline 20 & Solution formation & 4.10 & 63.06 \\
\hline 21 & Colligative properties & 3.80 & 50.88 \\
\hline 22 & Colloids & 3.77 & 71.93 \\
\hline 23 & Metal and metallurgy & 3.82 & 60.04 \\
\hline 24 & Nonmetal materials & 3.90 & 56.53 \\
\hline 25 & The definition and determination of reaction rate & 4.05 & 56.43 \\
\hline 26 & The rate law and reaction mechanisms & 4.07 & 59.75 \\
\hline 27 & The factors affecting reaction rate & 4.04 & 67.64 \\
\hline 28 & Chemical equilibrium & 4.22 & 45.42 \\
\hline 29 & The application of equilibrium constant & 3.99 & 45.32 \\
\hline 30 & Qualitative treatment: Le Chatelier's Principle & 4.05 & 51.66 \\
\hline
\end{tabular}

